\title{
Why Social Comparison on Instagram Matters: Its impact on Depression
}

\author{
Ha Sung Hwang \\ Department of Media and Communication, Dongguk University \\ Seoul, South Korea \\ [e-mail: hhwang@dongguk.edu] \\ *Corresponding author: Ha Sung Hwang \\ Received October 3, 2018; revised January 9, 2019; accepted February 28, 2019; \\ published March 312019
}

\begin{abstract}
Social Networking Sites (SNS) provide people with unique online social interaction environments where users can disclose their thoughts, feelings, and opinions to their personal contacts. Although previous studies have suggested that such activities produce positive effects on SNS user well-being, this study considered potential negative effects by investigating the relationship between SNS use and depression. In particular, This stydy examined how specific activities are related to different types of social comparison (upward/downward/horizontal) and how these different types of social comparison influence depressed moods among college students. The analysis of a survey of 245 Instagram users found that (1) looking at other people's status updates and commenting on other people's photos influences upward social comparison, (2) frequency of Instagram use predicts upward/downward/horizontal social comparison, and (3) upward social comparison was postively associated with depression, while downward social comparison was negatively associated with depression. Furthermore, the path anlaysis show that social comparison mediates the effect of Instagram use on depression. It suggests that Instagram use does not directly increase depression but it can lead to depression when social comparison on Instagram triggers depression.
\end{abstract}

Keywords: Instagram, social comparison, SNS, Depression

A preliminary version of this paper was presented at APIC-IST 2018, and was selected by the conference review process 


\section{Introduction}

Social Networking Sites (SNSs) have become key tools for communicating and sharing information with other people. By sharing personal thoughts, pictures, and accomplishments, hundreds of millions of people every day use these sites to maintain relationships and expand their social networks. SNSs enable people to create profiles containing information about themselves (e.g., pictures, interests). Features such as "status updates" and "tweets" allow SNS users to give other people glimpses into their daily lives [1].

The growing popularity and increasingly frequent usage of SNSs has prompted researchers to begin examining how SNSs affect user psychological well-being. However, the research to this point has yield mixed result. For instance, Kim and Lee (2011) studied the relationship between the amount of SNS use and emotional well-being, aiming to determine whether SNS use directly influenced happiness [2]. They reported that use of Facebook could improve the life satisfaction of adolescents because it provides an avenue for social support. Similarly, Ellison et al. (2007) found that Facebook use affects satisfaction with life and subjective well-being [3]. Because people use SNSs to fulfill a variety of social needs including self-expression and self-presentation [4] [5], such activities on SNSs can increase user's self-esteem and positively affect well-being [6] [7]. Additionally, Lee et al. (2013) found that people who perceive higher levels of social support on SNS have more sustained positive emotions and ultimately experience increased life satisfaction [8]. These studies confirm that SNSs play a role in supporting and building social relationships and that increased SNS interaction can contribute positively to happiness and satisfaction in life [9].

On the other hand, because many people are concerned about others' impressions of them and try to manage these impressions in favorable ways, SNS users present themselves positively by posting pictures in which they look their best or appear to be having a good time with their friends or family members [10]. Generally, users spend a lot of time on SNSs viewing the idealized SNS profiles, pictures, and status updates of others [11] .Exposure to information about how others are doing can influence self-perceptions-how individuals see themselves. Festinger (1954) first examined the process of self-evaluation based on comparison with information about other people, calling this phenomenon social comparison. Researchers applying social comparison theory have since posited the existence of various motivations for people's fundamental need to evaluate themselves [12]. For example, research has shown that people compare themselves with those they perceive as having positive characteristics (upward social comparison) out of a desire to become more like their comparison targets[13], whereas people compare themselves to those they perceive as inferior (downward social comparison) to improve self-evaluations[14] .

As online interaction has increased, researchers have suggested that SNS users engage in social comparison, using the personal information contained in photos and posts as bases for upward or downward comparisons [15]. Recent studies have supported this view. Facebook use has been shown to affect both users' impressions of others and self-perceptions. For instance, people who have used Facebook longer easily remember positive messages and happy pictures that other people post on Facebook and such available examples give users the impression that other people are happier than them. Moreover, users have reported that they regard life as less fair [16].

Other studies have found that comparing oneself to others significantly impacts SNS users' well-being. For example, one study found that active use of Facebook (e.g., writing a status 
update or commenting on a friend's post) influences user depression levels, showing, specifically, that Facebook envy mediates such negative feelings. Research has implied that Facebook use can lead to depression when users envy others [17]. Other studies have also found that "envy feelings are often triggered by following information of others on Facebook" [18]. Thus, it appears that users view SNSs as idealized places to facilitate negative social comparison [19].

Despite the possibility that SNSs make social comparison easy, a systematic understanding of how social comparison affects users' well-being remains elusive. Indeed, Vogel et al (2015) stated that "even if we acknowledge that social comparison is occurring[15], we know very little about what specific content people are evaluating and how this impacts well-being (e.g., pictures, comments, friend activity)" (p. 255). This study aims to fill current research gaps by examining how specific SNS activities affect users' social comparison experiences in the context of Instagram. It sought to determine, for example, whether different types of user activities (passive /active) result in different types of social comparison.

In addition, although previous studies of social comparison on SNS have treated it as a negative experience that can lead to depression, few studies have conceptualized social comparison in detail. This study addressed this gap by examining three specific dimensions of social comparison (upward, horizontal, and downward social comparison) and empirically testing how they influence users' feelings of depression.

Building on previous research examining the impact of Facebook on users' self-perceptions, this study specifically examined how social comparison affects the relationship between Instagram use and users' depression. Instagram has captured the interest of many adolescents and young people around world. Recent reports have indicated that Instagram has more than 800 million active monthly users [9]. Despite the growing popularity of Instagram, however, prior research has concentrated primarily on social comparison on Facebook. This study sought to fill this research gap by examining social comparison in the Instagram context. In other words, the study aimed to determine whether Instagram use encourages unfavorable social comparisons, which may in turn lead to depressed moods among college students.

The next section presents a review of relevant literature, emphasizing the theory of social comparison and its effects on SNS. Section 3 introduces our research questions. Section 4 explains the methods used in this study, highlighting the samples and measures of important variables. Section 5 presents our findings. Finally, section 6 discusses the implications of our findings, explains the study's limitations, and suggests possible directions for future research.

\section{Literature Review}

\subsection{Social Comparison Theory}

Social comparison theory, developed by Festinger (1954) [12], states that people have an inherent drive to accurately evaluate their opinions and abilities, and that people compare themselves to other people if objective evaluations are not available. The theory's basic premise is that people want to evaluate their abilities and opinions and that one way to accomplish this desire is to compare themselves to other people [12]. Individuals can use the information generated from these comparisons to gain insight into their capacities and limitations. However, under certain circumstances, the information produced by such comparisons can generate self-threats [20] [21] [14]; moreover, studies have shown that such self-threats can lead to negative outcomes such as depression [23] [24] [25]. For instance, if people compare themselves with others who are better or worse off than they are, these 
comparisons impact subjective well-being [25] [14]' Therefore, social comparison plays an important role in determining how people evaluate themselves [26].

Social comparison can be classified into three different types that have different functional purposes: horizontal (or nondirectional), downward, and upward. Horizontal, or nondirectional, comparison refers to comparisons between equals and is most useful for collecting information about the self. Research has indicated that people are more likely to compare themselves to those who are more similar to them [14]. People also often compare themselves with those who are worse off. Such downward social comparison involves comparing oneself to those who one perceives as lower-performing than oneself. Because it tends to improve self-esteem, downward social comparison has been associated with positive mental health outcomes such as decreased anxiety and positive affect [27]. Lastly, upward social comparison (also known as negative social comparison) involves comparing oneself with people one perceives as higher-performing than oneself. Festinger (1954) asserted that, in Western culture, it is desirable to be slightly above average and to constantly improve one's abilities. Sometimes such upward comparison can produce threats to the self and such self-threats may generate negative outcomes[13] [23] [24] [28]. Moreover, prior research has indicated that such upward social comparisons relate to people's psychological well-being, influencing individual levels of depression or life satisfaction.

Some studies have shown that people who are more likely to practice upward social comparison experience decreased positive affect [29]. Studies have also indicated that performing poorly increases one's vulnerability to upward social comparison. For instance, Whitehead \& Smith (1986) reported that if people receive negative feedback from others, they are more likely to be concerned with self-presentation and, as a result, engage in more upward social comparisons [30].

\subsection{Social comparison, SNS and depression}

The fact that SNSs allow users to gain insights into their SNS friends' lives makes SNSs ideal platforms for social comparison. Previous studies have examined how social comparison on Facebook relates to indicators of subjective well-being, such as depression [31] and envy [32]. Some research has found links between Facebook use and depressive symptoms through the mediator of social comparison [27]

Facebook has gained popularity as a leading SNS. It allows users to "friend" each other, usually people they know, see other people's posts in a news feed, and "like" posts and pages. In general, Facebook users tend to post the most self-enhancing content on their profiles. Posting such content may boost one's own well-being, but research has shown that viewing large quantities of one's friends' ideal representations can lead to negative emotions and the feeling that one is alone in those negative emotions [27].

Several studies have suggested that social comparison has negative effects on SNS users' lives. For instance, research has shown that viewing the Facebook profile of a friend who is physically attractive or has a successful career negatively impacts users' self-perceived attractiveness and self-perceived career success [33]. Research has also shown a positive association between the number of hours college students use Facebook and depression [34]. Such depression has been shown to increase when users engage in social comparison [36].

Meanwhile, other research has also examined social comparison as a mediator in the relationship between time spent on Facebook and depressive symptoms [36]. In their study of 152 college students, Steers and his colleagues (2014) found that, when SNS interaction causes users to feel that other people have better lives than they do [36], they feel more 
depressed [36]. In particular, by analyzing the three types of social comparison (upward, horizontal, and downward) separately, Steers et al. (2014) found that all three types were significant mediators in the relationship between Facebook use and users' depression. Similarly [36], Vogel et al. (2014) found a greater degree of upward social comparison on Facebook than downward social comparison [15], and this upward social comparison through Facebook significantly mediated the relationship between Facebook use and users' self-esteem [15].

\subsection{Instagram}

Since its debut in October 2010, Instagram, a mobile-based photo-sharing application, has quickly become a leading SNS. On an average day, more than $60 \%$ of Instagram users log on to the site and users around the world update 95 million photos and videos. Instagram attracted more than 800 million active monthly users [9]. Young people constitute the majority of users. By analyzing the images that five young people aged 22-25, posted on Instagram, Marcus (2015) concluded that Instagram exists to enable personal self-promotion. Indeed, "selfies"-photographs that individuals take of themselves [37], typically with webcams or smartphones - are among the most popular types of posts. Marcus (2015) insisted that unlike Facebook, Instagram is based more on one's personal identity than one's relational identity [35]. Among the features that make it distinct from Facebook, creating new content requires posting a photo or video. For instance, on Instagram people create public profiles that other users can "follow," enabling people they do not know personally to view, like, and comment on their photos. The unique "hashtag" feature allows users to promote following and/or being followed by strangers, regardless of user privacy settings, making all photos with a given hashtag searchable. Thus, by clicking, editing, and uploading photos instantly, users share moments from their daily lives with others in real time on Instagram.

Scholars have argued that the image-driven nature of Instagram encourages presentation of only the most positive and polished characterizations of one's life [36]. The resulting prominence of positive images may trigger assumptions that these photos are indicative of how the people in them actually live and thus make people more vulnerable to judging themselves in relation to the assumed (but often unrealistic) lives of others, which can trigger negative feelings (e.g. depression and stress).

\section{Research Questions}

Although researchers have examined the social comparison process in traditional contexts (e.g., face-to-face) and in some SNS contexts (e.g. Facebook), to our knowledge, researchers have yet to examine social comparison in the context of Instagram. After logging on, Instagram users are continuously exposed to a variety of information-profiles, uploaded photos, friends' status updates, likes, etc. These activities may prompt users, especially those who spend more daily time on or more frequently use Instagram, to automatically engage in upward/downward or horizontal social comparison. This study, therefore, investigates these issues by proposing the following research question:

RQ1: How does Instagram use (daily time spent and frequency) and activities (updating profiles, posting photos, reading other's status) predict different types of social comparison (upward, downward, and horizontal)? 
As discussed above, previous research has demonstrated that engaging in social comparison on Facebook produces negative outcomes. Additionally, past studies have indicated that such social comparison may serve as a mediator between time spent on Facebook and depressive mood. This study addressed these issues in the context of Instagram use. Given that no previous studies have separately examined the relationships between specific types of social comparison and depression, this study proposed research questions instead of hypotheses to examine them.

RQ2: How do different types of social comparison (upward, downward, and horizontal) predict depression among college students?

RQ3: Does social comparison mediate the relationship between Instagram use and depression?

\section{Method}

\subsection{Participants}

The study used the survey method. Participants was recruited from classes in a university in South Korea, because Koreans in their 20s and 30s are generally considered heavy users of Instagram. Only students who had Instagram accounts could participate in the study. A total of 245 participants completed surveys. Participants included 119 males (45\%) and 126 females (55\%), with an average age of 22.51 years $(\mathrm{SD}=1.89)$. One third of them were juniors (31.8\%), followed by seniors (27.2\%), sophomores (25.8\%), and freshmen (17.2\%).

\subsection{Measures}

\subsubsection{Instagram use}

To measure Instagram use, two related constructs were used: frequency of Instagram use and daily use of Instagram. First, to assess frequency of Instagram use, the survey asked respondents the following question with responses based on a five-point scale where $1=$ never, $5=$ often: "How often do you use Instagram?" Second, to assess daily use, the survey asked respondents the following question adapted from previous studies [36] with responses based on a five-point scale (10 minutes or less, 11-30 minutes, 31-60 minutes, 1-2 hours, and 2-3 hours by adapting previous studies): "Approximately how many minutes do you spend on Instagram daily?” The responses to these two questions were then combined to make a composite Instagram use index for the final analysis (Cronbach's alpha $=.89$ )

\subsubsection{Instagram activity}

To measure Instagram activity, four items were adopted from previous studies of Facebook. They asked respondents to answer the following questions based on five-point Likert-type scales ( $1=$ never $5=$ very frequently): "How often do you update your Instagram profile/ status?," "How often do you post photos?," "How often do you look at other people's status updates?," and "How often do you comment on other's photos?" 


\subsubsection{Social comparison on Instagram}

To assess respondents' social comparison on Instagram, the study asked participants to respond to 6 items. It was designed a pair of items to assess each different type of social comparison: upward, downward, and horizontal. Participants indicated their agreement with the items using five-point Likert-type scales (1=strongly disagree, $5=$ strongly agree). The items were the following: "I prefer to compare myself to other people on Instagram whose performance or abilities are better than mine" and "I prefer to compare myself with other people on Instagram whose lives are better than mine" (upward social comparison); "I prefer to compare myself to other people on Instagram whose performance or abilities are worse than mine" and "I prefer to compare myself with other people on Instagram whose lives are worse than mine" (downward social comparison); "I prefer to compare myself to other people on Instagram whose performance or abilities are similar to mine" and "I prefer to compare myself to others on Instagram whose lives are similar to mine" (upward social comparison). It was computed each social comparison index by adding each pair of items. The index was reliable: upward $\alpha=.89$, downward $\alpha=.91$, and horizontal $\alpha=.91$.

\subsubsection{Depression}

To assess respondents' depression, ten items selected from previous studies [17] [37] were used. These included: "I often lose my appetite," "I often feel I am depressed," "I often feel that there is nothing nice I can look forward to," "I often think my life has been a failure," and "I have trouble keeping my mind on what I am doing." Respondents indicated their levels of agreement with each item using a five-point Likert scale ( $1=$ strongly disagree; $5=$ strongly agree). The study then combined the responses into a composite score. The index was reliable $(\alpha=.85)$.

\subsubsection{Demographic variables}

Respondents were asked to report their genders, ages, and academic levels.

\section{Results}

\subsection{The impact of Instagram use on Social comparison}

The study used SPSS 20.0 software to analyze the data. In examining the first research question, multiple regressions were conducted to determine how Instagram use predicted social comparison. The independent variables were frequency of Instagram use, daily time spent using Instagram, and four specific activities (updating profiles/status, posting photos, looking at other people's status updates, and commenting on other people's photos), and the dependent variables were the three types of social comparison (upward, downward, horizontal).

First, in predicting upward social comparison, the result showed that frequency of Instagram use $(\beta=0.28, p<0.01)$, looking other people's status updates $(\beta=0.19, p<0.05)$, and commenting on other people's photos $(\beta=0.15, p<0.05)$ were significant predictors. These predictors are accounted for $26 \%$ of the variance in Instagram use on upward social comparison $\left(\mathrm{R}^{2}=0.26, \mathrm{~F}=23.51\right)$ and the regression model was significant at the 0.001 level. 
In predicting downward social comparison, the result showed that only frequency of Instagram use $(\beta=0.14, p<0.05)$ was a significant predictor. The regression model was significant at the the 0.001 level by explaining $24 \%$ of the variance in Instagram use on downwarod social comaprison $\left(\mathrm{R}^{2}=0.24, \mathrm{~F}=14.95\right)$.

On the other hand, daily time spent using Instagram $(\beta=0.16, p<0.05)$ and frequency of Instagram use $(\beta=0.13, p<0.05)$ appeared as significant predictors of horizontal comparison. These predicors accounted for $11 \%$ of the variance in Instagram use on horizontal social comparison $\left(\mathrm{R}^{2}=0.11, \mathrm{~F}=9.78\right)$. The regression model was significant at the 0.001 level.

Taken together, these findings indicate that the daily amount of time spent using Instagram and the frequency of Instagram use influence all types of social comparison. In addition, they also suggest that users who spend more time looking at other people's status updates or commenting on other people's photos are more likely to experience upward social comparison than other types of comparison.

\subsection{The impact of Social comparison on Depression}

The second research question asked how different types of social comparison predicted depressed moods. Multiple regression was performed to examine this question. The independent variables were the three types of social comparison (upward, downward, and horizontal) and the dependent variable was depression.

The findings show a positive association between upward social comparison and depression ( $\beta=0.34, p<0.001$ ); but a negatvie association between downward social comparison and depression $(\beta=-0.21, p<0.01)$ was found. These two prediocts accounted for $14 \% \%$ of the variance in social comparison on depression $\left(\mathrm{R}^{2}=0.14, \mathrm{~F}=20.80\right)$. This regression model was significant at the 0.001 level. However, the study found no significant direct relationship between horizontal comparison and depressed mood among college students.

These finding implied that the more respondents engaged in upward social comparison on Instagram, the more depressed they felt, while the more respodents experienced downward social comparison on Instagram, the less depressed they felt.

\subsection{The mediating role of social comparison}

The third research question concerned the role of social comparison in the effects of Instagram use on depression. Specifically, the question asked if social comparison mediates the relationship between Instagram use and depression. We used a mediation model to test the prediction that social comparison mediates the relationship between Instagram use and depression. For this analysis, Instagram use index was developed by combining two items (frequency of Instagram use and daily time spent using Instagram), and a social comparison index by combining all the items we used to measure the different types of social comparison. Then the study followed Baron and Kenny's approach (1986) to test the mediational role of social comparison. First, the study tested a simple model with a direct path between Instagram use and depression [38]. The path coefficient between them was not significant. However, when added social comparison as the mediating variable, the effect of Instagram use on depression proved significant. This analysis confirmed the mediating role of social comparison. In particular, the result showed that Instagram use predicts social comparison ( $\beta=$ $0.10, p<0.01)$, which then predicts depression $(\beta=0.42, p<0.01)$. This finding implies that Instagram use may not directly influence depression but it can lead to depression when social comparison on Instagram triggers depression. 


\section{Conclusion}

Previous studies have suggested that SNS use is positively related to users' life satisfaction through social capital (e.g. strong and weak ties). With regard to social interaction on SNS, research has pointed to a poor-get-richer effect in which college students who are less satisfied with their lives may benefit from increased online interaction [39]. Although these studies have provided some clues about the advent of SNSs, researchers have yet to definitively determine whether SNSs facilitate more complex levels of online interaction, resulting in a new context for young people to engage in social comparison and in turn leading to negative feelings. Therefore, in contrast to previous studies, this study attempted to understand the social comparison dynamics on SNSs in general and on Instagram in particular.

The study found an association between Instagram use and social comparison: in particular, increased frequency of Instagram use increased all types of social comparison. This finding implies that if college students log on to Instagram frequently, they automatically begin comparing themselves with others who are better or worse off than or similar to them. These findings support previous research focused on Facebook social comparison [26]. Given that SNSs facilitate interaction with and feedback from other people, as well as user self-disclosure in the creation of profiles, the fact that users consistently compares themselves with others while viewing other people's SNS content is not surprising.

In addition, the study's findings suggest that the outcomes of social comparison on Instagram are a function of user activities. In other words, it was found that looking at other people's status updates and commenting on other people's photos/videos were strongly associated with upward social comparison. These results support the findings of Krasnova et al. (2013) regarding the relationships between envy and Facebook activity [18]; they discovered that passive following activity (e.g., browsing other people's profiles, viewing friends' conversations, and watching news feeds) impacted users' feelings of envy on Facebook. Other studies have also found that SNS investment (e.g. frequency of visiting SNSs, making new friends on SNSs, and changing profiles) decreased users' self-esteem [39]. Combining these findings, it appears that although these activities are regarded as passive participation, such activities are dominant on SNSs and lead to negative feelings. Therefore, future studies should consider different types of SNS user activities as independent variables without combining them into one general variable. The limited available research about the relationships between specific SNS activities and separate types of social comparison (instead of general social comparison) highlights the need for additional research to reexamine our findings.

Moreover, our analysis revealed that social comparison on Instagram impacts feelings of depression. In particular, when users view photos of others, and feel that others have better lives than they do or others are doing better than they are, such upward social comparison increased depressed feelings. These results complement the findings of previous studies that examined the relationship between the intensity of SNS use and loneliness. However, the study's findings suggest that if users engage in more downward comparisons on Instagram, they become less depressed. Althoguh previous studies argued that engaging frequently in social comparisons of any kind (upward, downward, or horizontal) may be related to lower psychological well-being [26], our findings show that downward social comparison decreased loneliness. Therefore, future studies should reexamine the relationships between different tyeps of social compaison and depression.

Finally, the study found that social comparison plays a mediating role in the effect of Instagram use on depression. The analysis indicated that frequently logging on to Instagram and/or spending more time on Instagram provides users with the opportunity to spontaneously engage in Instagram social comparison (of any kind), which in turn is associated with greater 
depressive mood among college students. This result indicates that social comparison on Instagram can be detrimental to young people's self-perceptions. On a practical level, these findings imply that the more young people engage in everyday Instagram use the more likely they are to engage in social comparison, which, in turn, could have negative effects on their well-being.

This study did have several notable limitations. First, there are many ways to capture Instagram use and we only used frequency of Instagram use. Therefore future studies should consider another approach to examining Instagram use, perhaps developing Instagram-use intensity measures, which could be based on social contacts such as number of friends or followers. By employing additional definitions of Instagram use, future studies could reexamine the relationship between Instagram use and social comparison and depression.

Second, the survey method introduces the problem of over-reliance on self-reporting. Although the study used reliable and validated variable scales (e.g., depression, social comparison), some respondents might not have reported the actual extent to which they experienced the variables, since in answering questionnaire items they needed to rely on memory.

Third, since this study was conducted in Korea, the results may not be generalizable to other cultural contexts. Moreover, due to our use of convenience sampling, our findings may not be generalizable to the entire population of college students. Therefore, future studies should examine social comparison processes using more diverse samples (e.g. different age groups and cultures).

In addition, future studies may consider alternative approaches to investigating the study's findings; for example, future researchers could adopt an experimental design whereby college students are exposed to researcher-created Instagram profiles manipulated to convey different types of social comparison (upward and downward) information.

Finally, although the findings indicate that specific activities on Instagram produce specific types of social comparison, the study may have missed complex processes or important factors that explain the dynamics of social comparison. Future studies should consider other diverse variables such as demographic (e.g., personality, gender), social environmental (different level of participation to offline activity), and psychological factors (loneliness).

Despite these limitations, the study's findings help expand scholarly understanding of how and why social comparison occurs on SNS and what outcomes it produces. The examination of social comparison phenomenon on Instagram contributes to the discourse by extending previous research that focused on social comparison only on Facebook. Therefore a major contribution of the present study is that it provides evidence that online interaction on Instagram may indeed negatively impact users’ psychological states.

In conclusion, this study confirmed the notion that SNS use encourages unfavorable social comparison, which may in turn lead to depressive feelings. However, additional research analyzing such factors as other SNS activities (e.g. liking, following) and user characteristics (e.g. age, gender, and personality) remains necessary to advance our understanding of social comparison and depression on Instagram.

\section{References}

[1] J. Worthan “Feel Like a Wallflower? Maybe It’s Your Facebook Wall,” New York Times, April 9.2011. Article (CrossRef Link)

[2] J. Kim, and J. Lee. "The Facebook paths to happiness: effects of the number of Facebook friends and self-presentation on subjective well-being," CyberPsychology, Behavior, and 
Social Networking, vol. 14, pp.359-364. 2011. Article (CrossRef Link)

[3] N. Ellison, C. Steinfield , C. Lampe " The benefits of Facebook "Friends": Social capital and college students' use of online social network sites," Journal of Computer-Mediated Communication Vol. 12.pp.1143-68. 2007. Article (CrossRef Link)

[4] Back, M, J. Stopfer, S. Vazire, S.Gaddis, S. Schmukle4, B. Egloff1, and S. Gosling "Facebook Profiles Reflect Actual Personality, Not Self-Idealization," Psychological Science, vol.21 No. 3, pp. 372-74, 2010. Article (CrossRef Link)

[5] S. Gosling, S. Gaddis, and S. Vazire "Personality Impressions Based on Facebook Profiles," Paper presented at the International Conference on Weblogs and Social Media,vol.3.pp. 26-28, 2007. Article (CrossRef Link)

[6] A. Gonzales, and J. Hancock "Mirror, Mirror on My Facebook Wall: Effects of Facebook Exposure on Self Esteem," Cyberpsychology, Behavior, and Social Networking,vol.14, pp.79-83, 2011. Article (CrossRef Link)

[7] p. Valkenburg, p. Jochen, \& p. Schouten " Friend networking sites and their relationship to adolescents' social self-esteem and well-being," Cyber Psychology and Behavior, vol.9, no. 5, pp.584-590, 2006. Article (CrossRef Link)

[8] K. Lee, M. Noh, D. Koo "Lonely people are no longer lonely on social networking sites: The mediating role of self-disclosure and social support," Cyberpsychology, Behavior, and Social Networking, ,Vol. 16, No. 6,pp. 413-418, 2013. Article (CrossRef Link)

[9] Statista, Number of monthly active Instagram users from January 2013 to September 2017(in millions), Retrieved from https://bit.ly/2ea0AHs,2017.

[10] S. Zhao, S. Grasmuck, \&J. Martin, "Identity construction on Facebook: Digital empowerment in anchored relationships," Computers in human behavior, vol.24,no.5, pp.1816-1836, 2008. Article (CrossRef Link)

[11] T. Pempek, Y. Yermolayeva, \& S. Calvert, "College students' social networking experiences on Facebook," Journal of applied developmental psychology, vol.30,no.3, 00.227-238,2008. Article (CrossRef Link)

[12] L. Festinger, "A theory of social comparison processes," Human Relations, vol.7, pp.117-140, 1954.

[13] L. Penelope,K. Ziva, "Superstars and me: Predicting the impact of role models on the self”, Journal of personality and social psychology, Vol .73,no.1,pp.91-103,1997.

[14] T. Wills, "Downward comparison principles in social psychology," Psychological Bulletin, vol.90, no.2, pp.245-271, 1981. Article (CrossRef Link)

[15] E. Vogel, J. Rose, L. Roberts,\& K. Eckles, "Social comparison, social media, and self-esteem,” Psychology of Popular Media Culture, vol. 3,no. 4, pp. 206-222, Oct 2014.

[16] H. Chou, and N. Edge, "They are happier and having better lives than I am”: the impact of using Facebook on perceptions of others' lives," Cyberpsychology, Behavior, and Social Networking, Vol. 15, No. 2,pp. 117-121, Feb 2012. Article (CrossRef Link)

[17] E. Tandoc, P. Ferrucci, \& M. Duffy, "Facebook use, envy, and depression among college students: Is facebooking depressing?" Computers in Human Behavior, vol. 43, pp. 139-146, 2015. Article (CrossRef Link)

[18] H. Krasnova, H. Wenninger, T. Widjaja, \& P. Buxmann, "Envy on Facebook: A hidden threat to users' life satisfaction?” Available under License BORIS Standard License, vol. 27, pp. 02-01, 2013. Article (CrossRef Link)

[19] H. Appel, L. Alexander, and J. Crusius, "The interplay between Facebook use, social comparison, envy, and depression," Current Opinion in Psychology, vol. 9, pp. 44-49, June 2016. Article (CrossRef Link) 
[20] S. Morse, \& K. Gergen, "Social comparison, self-consistency, and the concept of self," Journal of Personality and Social Psychology, vol. 16,no. 1, pp. 148-156, 1970. Article (CrossRef Link)

[21] T. Mussweiler, \& G. Bodenhausen, "I know you are but what am I? Self-evaluative consequences of judging in group and out group members," Journal of Personality and Social Psychology, vol. 82, no. 1,pp. 19-32, 2002. Article (CrossRef Link)

[22] P. Brickman, \& R. Bulman, "Pleasure and pain in social comparison. In J. M. Suls \& R. L. Miller(Eds.), Social comparison processes: Theoretical and empirical perspectives,” Washington, D.C.: Hemisphere, pp. 1489-186, 1977.

[23] T. Mussweiler, S. Gabriel, \& G. Bodenhausen, "Shifting social identities as a strategy for defecting threatening social comparisons," Journal of Personality and Social Psychology, vol. 79, no.3, pp. 398-409, 2000. Article (CrossRef Link)

[24] P. Salovey, \& J. Rodin, "Some antecedents and consequences of social-comparison jealousy,” Journal of Personality and Social Psychology, vol. 47, pp. 780-792, 1984. Article (CrossRef Link)

[25] F. Gibbons, \& M. Gerrard, "Effects of upward and downward social comparison on mood statesm” Journal of Social and Clinical Psychology, vol. 8, pp. 14-31,1989. Article (CrossRef Link)

[26] H. Wayment, \& S. Taylor, "Self-evaluation processes: motives, information use, and self-esteem,” Journal of Personality, vol. 63, pp. 729-757, December 1995. Article (CrossRef Link)

[27] M. Steers, R. Wickham, L. Acitelli,, "Seeing everyone else's highlight reels: how Facebook usage is linked to depressive symptoms," Journal of Social and Clinical Psychology, Vol. 33, No. 8, pp. 701-731,2014. Article (CrossRef Link)

[28] B. Phillip and R. Bulman, "Pleasure and Pain in Social Comparison," in Social Comparison Processes: Theoretical and Empirical Perspectives, ed. Jerry Suls and Richard L. Miller, Washington, DC: Hemisphere, pp. 149-186,1977.

[29] E. Bäzner, P. Brömer, P. Hammelstein, \& T. Meyer , "Current and former depression and their relationship to the effects of social comparison processes," Results of an internet based study. Journal of Affective Disorders, vol. 93, no. 1-3, pp. 97-103, July 2006. Article (CrossRef Link)

[30] G. Whitehead,S. Smith, "Self-presentation as a determinant of upward comparison,” Representative Research in Social Psychology, vol. 16, no. 2,pp. 5-14, 1986. Article (CrossRef Link)

[31] B. Feinstein, R.Hershenberg,V. Bhatia, J. Latack, N. Meuwly, \& J. Davila, "Negative social comparison on Facebook and depressive symptoms: Rumination as a mechanism," Psychology of Popular Media Culture, vol, 2, no. 3, pp. 161-170, 2013. Article (CrossRef Link)

[32] H. Chou,\& N. Edge, "They are happier and having better lives than I am": the impact of using Facebook on perceptions of others' lives," Cyberpsychology, Behavior, and Social Networking, vol. 15,no. 2, pp. 117-121,2012. Article (CrossRef Link)

[33] N. Haferkamp, \& N. Krämer, "Social comparison 2.0: Examining the effects of online profiles on social-networking sites," Cyberpsychology, Behavior, and Social Networking, vol. 14, no. 5, pp. 309-314, 2011. Article (CrossRef Link)

[34] K. Wright, J. Rosenberg, N. Egbert, N. Ploeger, D. Bernard, \& S. King, “Communication competence, social support, and depression among college students: a model of facebook and face-to-face support network influence,” Journal of Health Communication, vol. 18, no. 1, pp. 41-57, 2012. Article (CrossRef Link) 
[35] S. Marcus, "Picturing'ourselves into being: assessing identity, sociality and visuality on Instagram," in Proc. of international communication association conference, Puerto Rico: San Juan. 2015.

[36] K. Lup, L. Trub, \& L. Rosenthal, "Instagram \#instasad?: Exploring associations among Instagram use, depressive symptoms, negative social comparison, and strangers followed. Social media predictors of depression," Cyberpsychology, Behavior, and Social Networking, vol. 18, no. 5, pp. 247-252, May 2015. Article (CrossRef Link)

[37] C. Neira, and B. Barber. "Social networking site use: Linked to adolescents' social self-concept, self-esteem, and depressed mood,” Australian Journal of Psychology, vol. 66, no. 1, pp. 56-64, December 2014. Article (CrossRef Link)

[38] R. Baron, \& D. Kenny, "The moderator-mediator variable distinction in social psychological research: Conceptual, strategic, and statistical considerations," Journal of Personality and Social Psychology, vol. 52, no. 6, pp.1173-1182, Dec. 1986. Article (CrossRef Link)

[39] N. Ellison, C. Steinfield, \& C. Lampe, "The benefits of Facebook "friends:” Social capital and college students' use of online social network sites," Journal of computer-mediated communication, vol. 12, no. 4, pp. 1143-1168, 2007. Article (CrossRef Link)

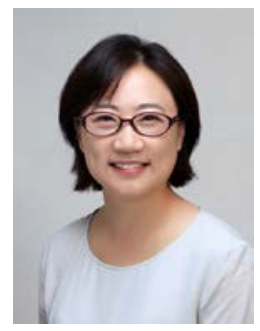

Ha Sung Hwang received her Ph.D. in Mass Media \& Communication at Temple University. She is a professor at Department of Media \& Communication at Dongguk University in Seoul, South Korea. Her research interests include social and psychological effects of communication technologies such as SNSs and digital media. Email: hhwang@dongguk.edu 